\title{
Alkaline Electrolysis with Skeletal Ni Catalysts
}

\author{
A.M. Fernández and U. Cano
}

Additional information is available at the end of the chapter

http://dx.doi.org/10.5772/50617

\section{Introduction}

\subsection{Hydrogen as a fuel: Properties and sources}

Hydrogen has been recognized as a potential energy vector for the energy future. Its high energy mass density (108,738 J/g, three times as much energy as 1 gram of gasoline), the possibility of obtaining hydrogen from many sources, the high efficiency with which its energy is extracted within fuel cells and converted into electricity, and the fact that its use does not produce any harmful emission, make of hydrogen the most attractive fuel for the new energy scenarios. These scenarios include high energy conversion efficiency technologies, zero emissions and use of sustainable and clean fuels.

The production of hydrogen needs both a hydrogen containing compound and energy to extract it. In general the processes used for its production can be divided in three: thermal, biological and electrochemical. In thermal processes, the most commercially developed, a hydrogen containing compound such as natural gas (i.e. methane) is catalytically transformed in the presence of water steam which provides thermal energy, a process known as methane steam reforming (MSR). The result of such reaction is a hydrogen rich mixture of gases which later go through an enriching (water shift reaction) and a purification stage (typically pressure swing adsorption or PSA). New processes less thermally demanded are being developed to lower hydrogen price. This type of process can also be used with different hydrogen containing compounds but the longer their molecules the more difficult is the extraction of hydrogen. In general MSR and other similar paths depend strongly on feedstock prices, i.e. natural gas prices, and are not $100 \%$ clean methods due to $\mathrm{CO}_{2}$ generated during hydrogen production. Some approaches to this, consider carbon sequestration in conjunction with clean electricity generation to gain from hydrogen benefits. Other thermal processes include chemical cycles where a "commodity" product (intermediate chemical compound) is generated to store primary energy in order to later use it for hydrogen production. Such processes are being explored but have not reached yet competitive costs compared to commercial hydrogen. 
In biological processes the activity of some living beings is either part of or completely responsible for the production of hydrogen. Some bacteria and other microorganisms, e.g. algae, are capable of generating hydrogen during their metabolism in their biological cycle. There have been hundreds of potential living systems identified that are able to generate hydrogen. Nevertheless, most of these are still under study as their production rates are low and costly. In electrochemical processes for the generation of hydrogen, photolysis is an attractive path as solar energy could be a cheap energy supply. Such systems are still in development and might arrive years ahead. The other alternative to steam reforming of methane with a commercial status is the electrolysis of water, from which two routes outstand, acid electrolysis and alkaline electrolysis. In the former, a solid acid electrolyte offers advantages as compact and less complex systems can be built. Despite acid electrolysis costs are decreasing, the maturity of alkaline electrolysis together with its generally lower costs can be advantageous as alkaline normally tend to use less noble metals as electrocatalyzer and in general kinetics tend to be better.

Once hydrogen is produced, its final use will determine whether the gas needs or not to be conditioned. In low temperature fuel cells hydrogen needs a high purity grade which gives electrolytic hydrogen an advantage over hydrogen from MSR which would need a purification stage. Electrolytic hydrogen from an alkaline process needs to scrub any traces of $\mathrm{KOH}$ to accomplish required purity. MSR on the other hand would not need a purification stage if produced hydrogen is going to a high temperature fuel cell, as its product can be directly fed for electricity production without much conditioning. If hydrogen is to be stored, either as a pressurized gas or in modern metallic hydride systems, hydrogen would need to be dried.

As it was mentioned above, the production of hydrogen needs a primary energy source and some type of feedstock from where hydrogen will be extracted. The combination of available primary energy sources and available feedstock give hydrogen production an almost infinite number of alternative routes. Nevertheless, electrolysis of water in combination with renewable primary energy resources is a very attractive scenario as the combination of both renewable energy and water could represent a real sustainable technology-ready alternative, especially considering that fuel cell technologies have gained credibility as a device to efficiently generate electricity from hydrogen fuel.

As an energy carrier hydrogen lends itself to build distributed generation (DG) systems to further gain efficiencies lost during traditionally centralized power plants for stationary applications like commercial or residential uses of electricity. Hydrogen is seen by many as an energy vector, similar to electricity, which can be produced in one place and consumed somewhere else. It may also be produced on-demand when economics are fulfilled. Transportation applications, for example, could have hydrogen stations where hydrogen does not need to be stored in large quantities nor needs to be transported if generated and dispatched locally.

All in all hydrogen is a very attractive path for sustainable societies, but technological and economic challenges still remain. One of these challenges includes hydrogen production at a 
competitive cost and those costs are directly related to the source of primary energy to produce it (up to $75 \%$ for alkaline electrolysis, according to the IEAHIA - [1]. With the blooming market of renewable energy technologies such as photovoltaic systems and wind energy turbines, electrolysis seems to have a great opportunity as a hydrogen production method. If this route accomplishes the renewable central hydrogen production cost goal of US\$2.75/gge (gasoline gallon equivalent) delivered, for 2015 established by hydrogen programs such as the HFCIT of DOE [2], no doubt we will see an increase in electrolysis products in the near future.

\subsection{Hydrogen storage}

Despite the fact that hydrogen presents a high energy density superior to that of conventional fuels, hydrogen is a gas difficult to compress as its compression also demands high energy in order to store it for its use. Nowadays storage tanks for hydrogen gas can be commercially bought for 350 and 700bar capacities. In its last Hydrogen and Fuel Cells Program Plan [2], the U.S. Department of Energy reported a novel "cryo-compressed" tank concept that achieved a system gravimetric capacity of $5.4 \%$ by weight and a volumetric system capacity of approximately $31 \mathrm{~g} / \mathrm{L}$. Nevertheless, the energy associated with compression and liquefaction needs to be considered for compressed and liquid hydrogen technologies. Other systems based on hydrogen absorbing materials and hydrogen compounds for storing hydrogen are been studied but their energy density (both weight and volume) still needs to reach competitive values to be considered a viable paths especially for mobile applications. Energy needed to extract hydrogen from some storage systems (for example solid-state materials) as well as their life cycle (metal hydrides) also would need to be cost competitive. Certainly hydrogen storage is still a challenge for many hydrogen applications which need yet to be addressed.

\section{Alkaline electrolysis}

Alkaline electrolysis is considered a mature technology with many decades of commercially available products for the production of hydrogen gas. This industry grew substantially during the 1920s and 1930s. Alkaline electrolysis can be described as the use of an electrical current passing through an electrolysis cell causing the decomposition of water to generate hydrogen gas on the cell's cathode. In an electrolysis cell two electrodes containing an electrocatalyst, separated by a physical barrier, a polymeric diaphragm which only allows the passing of ions from one electrode to another, are connected to a d.c. current source. Each cell will have a high specific active area due to its porous structure and will produce hydrogen gas at the cathode while oxygen will be produced in the anode. The electrodes are in contact with an electrolyte which provides $\mathrm{OH}^{-}$ions, from a $20 \%-30 \%$ solution of potassium hydroxide that completes the electrical circuit. In theory, $1 \mathrm{~kg}$ of hydrogen would need a little less than $40 \mathrm{kWh}$ of electricity. Although theoretical water decomposition voltage is $1.23 \mathrm{~V}$ (which corresponds to a theoretical dissociation energy of $286 \mathrm{~kJ} / \mathrm{mol}$ or 15.9 $\mathrm{MJ} / \mathrm{kg}$ at $25^{\circ} \mathrm{C}$ ), in practice this voltage goes normally to around $2 \mathrm{~V}$ per cell, while the total 
applied current depends on the cell's active area, and on the electrolyzer configuration (bipolar or unipolar). In the first case current densities $(\mathrm{A} / \mathrm{cm} 2)$ are higher than in unipolar configurations. There exist certain advantages in bipolar systems as they can operate under pressurized conditions, reducing or facilitating a compression stage. Higher current densities and generally a smaller foot-print are other positive characteristics of bipolar electrolyzers. As electrodes are placed closer, voltage drop from ohmic resistances are minimized saving in energy costs.

As mentioned earlier, there exist other electrolyzers that use a solid acid electrolyte based on an ionic conducting electrolyte. Those will not be treated in this document/section.

Electrode and global reactions in an alkaline electrolyzer are as follows:

$$
\begin{aligned}
& \text { Cathode: } 2 \mathrm{H}_{2} \mathrm{O}+2 \mathrm{e}^{-} \rightarrow \mathrm{H}_{2}+2 \mathrm{OH}^{-} \\
& \text {Anode: } 2 \mathrm{OH}^{-} \rightarrow 1 / 2 \mathrm{O}_{2}+\mathrm{H}_{2} \mathrm{O}+2 \mathrm{e}^{-} \\
& \text {Global reaction: } 2 \mathrm{H}_{2} \mathrm{O} \rightarrow \mathrm{H}_{2}+1 / 2 \mathrm{O}_{2}
\end{aligned}
$$

The operating temperature is typically around $80-90^{\circ} \mathrm{C}$ producing pure hydrogen $(>99.8 \%)$. Higher temperatures are being also used as the electrolysis of water steam decreases electricity costs. Pressure is another characteristic operating condition which goes from 0.1 to around $3 \mathrm{MPa}$. As with temperature, higher pressures help to decrease energy costs particularly as this generates high pressure hydrogen lowering compression energy when hydrogen will be stored or dispatched as a pressurized gas. Some approaches of cero pressure have been proposed generating then low pressure (about 40 bar -- [3]) hydrogen without any mechanical compressor. An approach to pressurized electrolyzers sometimes comprises a first stage where hydrogen is generated at about 200-500psi (13.8-34.5 bar) followed by a mechanical compression second stage to upgrade it to 5000psi (3447 bar). Commercial units often use nickel-coated steel in their electrodes but other proprietary materials are associated too to some products. The efficiency of alkaline electrolysis is about $70 \%$ LHV (Lower Heating Value), where hydrogen cost is associated to electricity costs, one of the main technological challenges along with the wholesale manufacture which also needs to improve in order to reach technology costs goals for competitiveness. Approximately a little less than 1 liter of de-mineralized water is needed to generate $1 \mathrm{Nm}^{3}$ of hydrogen. Once produced, hydrogen goes through a series of conditioning stages as seen in figure below (from [4]):

The main goal is to eliminate traces of $\mathrm{KOH}$, water and oxygen. In the system diagram shown the transformer/rectifier plays an important role in converting A.C. current to D.C. current which is actually the type of current involved in the electrochemical process of electrolysis. As mentioned earlier, the actual cost of hydrogen will be dependent on the source of electricity. Therefore renewable energy, especially as D.C. electricity, can greatly contribute to a more competitive hydrogen cost. It is reported also that electrolysis is better 
respondent to a load-following condition compared to other hydrogen production methods (e.g. MSR), making renewable energy related hydrogen a more suitable energy integrated system.

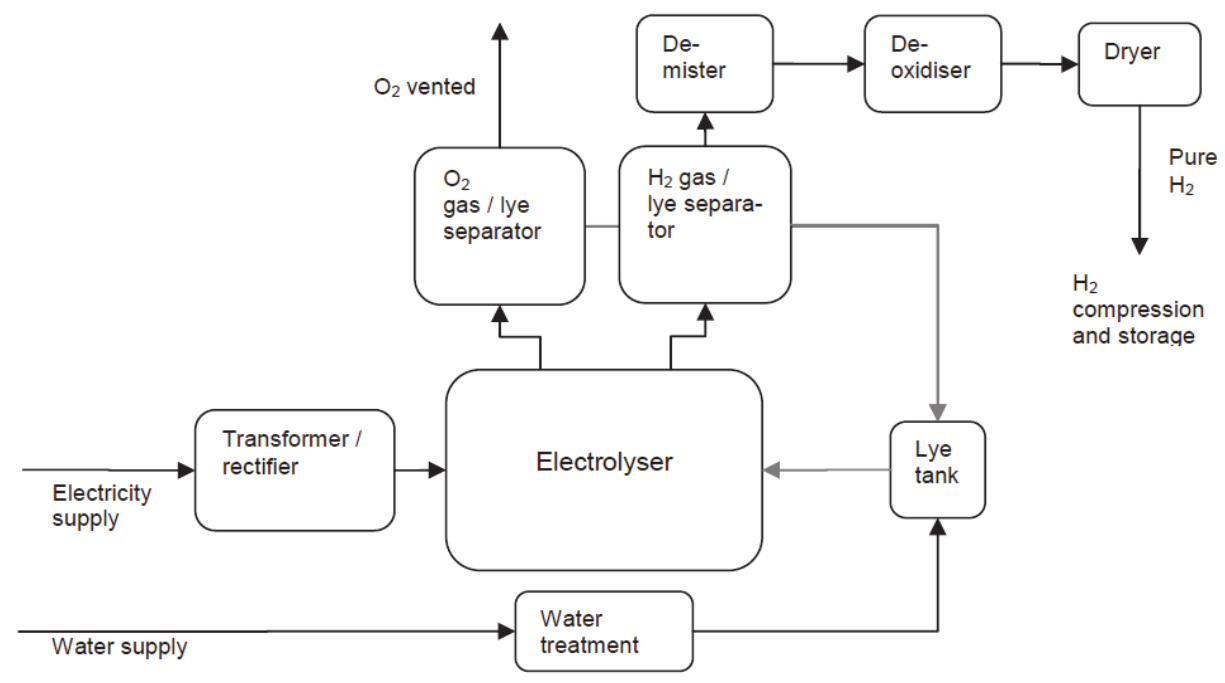

Figure 1. Schematic diagram of an alkaline electrolyzer [4]

\subsection{Alkaline electrolysis components:}

\subsubsection{Electrodes}

One of the materials most used in the hydrogen industry for alkaline electrolysis is nickel. This is due to its excellent catalysts properties and its corrosion resistance at the high $\mathrm{pH}$ values of $\mathrm{KOH}$ electrolyte in particular at the highly imposed anodic potential for the oxidation reaction. Often $\mathrm{Pt}$ alone or together with $\mathrm{Ni}$, is used in commercial products improving electrode kinetics performance but this increases the overall costs of the unit. Electrodes are manufactured so that they show a large electroactive area, therefore porous electrodes are normally made to produce large density currents and better hydrogen production rates. One type of nickel electrode material used is $\mathrm{Ni}$ Raney or skeletal $\mathrm{Ni}$, a material developed almost 100 years ago as a catalyst for hydrogenation of oils. Skeletal Ni is prepared from a Ni-Al alloy at specific concentration depending on the desired properties. This alloy is then leached in an alkaline solution to dissolve an aluminum containing phase leaving behind a porous structure. During the leaching process there is production of hydrogen which is said to remain in the porous making the resulting material pyrophoric and difficult to handle. Also the remaining aluminum can act as a trap for hydrogen as this metal is known to adsorb hydrogen molecules, which dissociate to produce hydrogen atoms within the metal- [6]. This hydrogen is believed to serve as a hydrogen"prepared" surface for the further hydrogen evolution process at the cathode regardless of 
the reaction mechanism [5]. The following figures show a microstructure of the Ni-Al alloy and its typical phases formed after alloying (a) and after the leaching process (b and c).

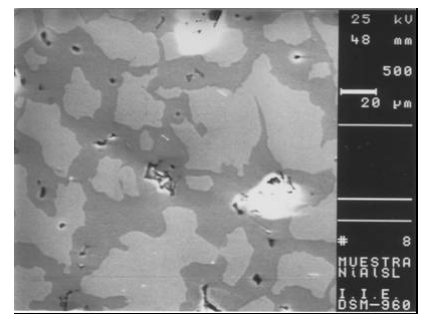

a) before leaching

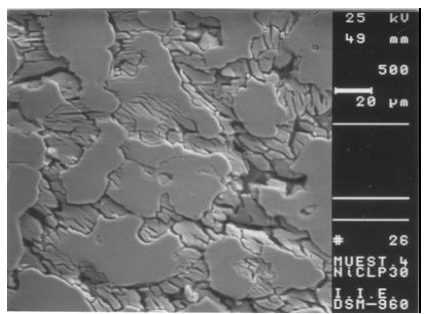

b) leached 30 minutes

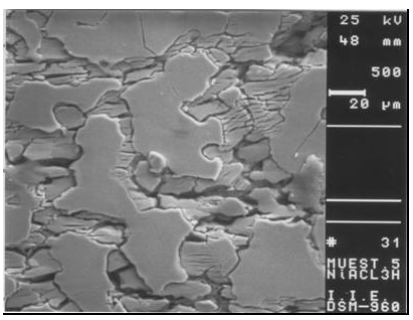

c) leached 3 hours

Figure 2. SEM micrographs (500X) showing microstructure of Nickel Raney electrodes and the leaching time effect in alkaline solution [5].

As nickel oxidizes in an alkaline solution forming oxides and hydroxides of the metal, it is also believed that most of the catalyst properties in Ni electrodes come from those phases. For example, Subbaraman et al. [7] combined nickel oxide and platinum to produce a more effective catalyst than either component alone. The authors propose a mechanism in which nickel helps to cleave the $\mathrm{O}-\mathrm{H}$ bond while platinum directs the separated $\mathrm{H}$ intermediates to form $\mathrm{H}_{2}$. Section 3 reviews some literature on different electrode systems researched in the last few years in order to make more effective and economically attractive electrodes.

\subsubsection{Electrolyte}

As mentioned earlier $\mathrm{KOH}$ solutions are used in alkaline electrolysis. This electrolyte is contained in a closed circuit to avoid contact with $\mathrm{CO}_{2}$ from the atmosphere that could impose an adverse technical challenge due to the precipitation of carbonates formed. The $\mathrm{KOH}$ concentration is very important as it determines the ionic conductivity that should remain high in order to avoid the use of higher voltages from ohmic losses. These losses could increase the energy use and therefore the hydrogen cost.

\subsubsection{Diaphragm}

In alkaline electrolysis a diaphragm is a separator which should keep a good ionic conductivity while effectively separating hydrogen and oxygen gases generated at the cathode and anode sides respectively. It typically consists of a matrix porous material which should chemically stand (and contain) a corrosive environment ( $25 \% \mathrm{KOH}$ solutions) at relatively aggressive temperatures $\left(\sim 85^{\circ} \mathrm{C}\right)$. It should also be mechanically strong to withstand changes in dimensions (compression) due to stresses associated to structural design and due to temperature changes. Although asbestos have been used for many decades, alternative polymeric matrixes are preferred by main developers due to the potential asbestos exposure health risks. Along with the economics in the selection of materials, efficient operation needs to be ensured by materials with low gas permeability, 
low ionic resistance (but high electronic resistance). The effective thickness, i.e. the product of MacMullin number and thickness of the matrix material, is normally determined while selecting diaphragms as it better represents its effectiveness. The MacMullin number, defined as the ratio of the specific resistivity of the electrolyte-saturated matrix material to the resistance of the same volume of electrolyte, can be obtained using Electrochemical Impedance Spectroscopy (EIS) measurements.

From the technical point of view there have been corrosion problems by the use of alkaline solutions in recent international projects, which turned into down time of the equipment. Nevertheless, this could be more a good engineering practice issue (for example materials selection) than a technological problem.

\section{Raney nickel and its alloys, as a catalytic material}

During alkaline electrolysis, there are three important reactions that may take place during the Hydrogen Evolution Reaction (HER). Depending on the mechanism, the HER in alkaline media is typically treated as a combination of two steps: the Volmer step-water dissociation (reaction 4) followed by either the formation of the reactive intermediate Had, Heyrovsky step (path in reaction 5) or the Tafel recombination step (path in reaction 6).

$$
\left.\begin{array}{c}
\mathrm{H}_{2} \mathrm{O}+\mathrm{M}+\mathrm{e}^{-} \rightleftarrows \mathrm{M}-\mathrm{H}_{\mathrm{ad}}+\mathrm{OH}^{-} \\
\mathrm{M}+\mathrm{H}_{2} \mathrm{O}+\mathrm{e}^{-} \leftrightarrow \mathrm{MH}_{\mathrm{ads}}+\mathrm{OH}^{-} \\
\mathrm{MH}_{\mathrm{ads}}+\mathrm{H}_{2} \mathrm{O}+\mathrm{e}^{-} \leftrightarrow \mathrm{H}_{2}+\mathrm{M}+\mathrm{OH}^{-}
\end{array}\right\}
$$

Nickel Raney electrodes have as main characteristic a high surface area but along its preparation its catalytic performance is enhanced to promote the hydrogen evolution reaction in alkaline media. Many element and compounds have been explored to further improve this feature. For example, compounds materials based on $\mathrm{NiCo}_{2} \mathrm{O}_{4}$ have been used to prepare, via electrodeposition, electrolysis electrodes [12]. This material was compared with Ni electrodes finding an exchange current density $\left(i_{0}\right)$ seven times larger, obtaining a good chemical stability in alkaline solutions. On the other hand, studies on Ni-Co alloys [13], also prepared by electrodeposition, have shown that the overpotential for the hydrogen evolution reaction is smaller when the material has Cobalt content between $41 \%-65 \%$ weight percent. Additional work [14], where Ni was alloyed with $47.7 \%$ weight percent $\mathrm{Co}$, showed good electrocatalyst activity and electrochemical studies revealed that the Volmer reaction is the controlling step of the hydrogen evolution reaction, promoting the $\mathrm{Ni}-\mathrm{H}_{\text {ads }}$ species formation. The roughness factor of $\mathrm{Ni}-\mathrm{Co} / \mathrm{Zn}$ [15] structures, prepared by electrodeposition followed by an alkaline $\mathrm{KOH} 1 \mathrm{M}$ leaching process, was evaluated using electrochemical impedance. It was observed that at high current densities the effective area and the active 
sites promoting the hydrogen evolution reaction are reduced. In this work another finding made was the fact that the lesser the Co content on the external surface, the less catalytic activity.

In a different work using bronze substrates, $\mathrm{Ni}$ and $\mathrm{Ni}$-Zn were electrodeposited [16] to obtain bronze/Ni, bronze/NiZn and bronze/Ni/NiZn configurations. NiZn electrodes were leached in alkaline media in order to obtain a porous electrode structure. Their major finding was the fact that the bronze/Ni/NiZn material showed a better corrosion resistance.

Nanocrystals of electrodeposited CoNiFe [17] were used to study the hydrogen evolution reaction by electrochemical impedance finding that the controlling reaction mechanism is via Volmer and then Tafel paths, where a Heyrosky stages was favored. The electrocatalytic activity of these nanocrystals depended on operating temperature.

Electrodes based on electrodeposited NiCoZn [18] showed better stability during studies. These electrodes were synthesized by electrodeposition of $\mathrm{Ni}, \mathrm{Co}, \mathrm{Zn}$, on a $\mathrm{Cu}$ substrate followed by a leaching stage in $\mathrm{NaOH}$, producing a compact porous structure. By electrochemical impedance and linear polarization resistance studies the authors suggest the formation of a passive layer on the electrodes surface allowing a better corrosion resistance but decreasing catalytic activity for the hydrogen evolution reaction. The addition of small quantities of noble metals such as $\mathrm{Ag}$, $\mathrm{Pd}$ and $\mathrm{Pt}$ to NiCoZn layers after the leaching process allows for a better catalytic activity. These studies showed NiCoZn-Pt electrodes with better catalytic activity. The use of noble metals limits an extensive use for these compounds as some of the components are not abundant in nature and their extraction and refining processes are expensive for hydrogen production.

For that reason metals like $\mathrm{Fe}$ to form $\mathrm{Ni}-\mathrm{Fe}$ are used to prepare electrodes by electrodeposition [19]. For these electrodes the alloy's Fe content has shown to determine the catalytic activity, while the hydrogen evolution reaction is controlled by the Volmer route. NiFe [20] electrodes were added with carbon loads in order to control the grain size and with this, the current density for hydrogen evolution in alkaline media. A carbon $1.59 \%$ weight percent produced a $3.4 \mathrm{~nm}$ grain size and the lowest overpotential for the HER at polarization current density $0.12 \mathrm{~A} / \mathrm{cm} 2$. In a layer by layer preparation of $\mathrm{Ni}-\mathrm{Fe}-\mathrm{C}$ electrodes on $\mathrm{Cu}$ [21], Tafel slope of $116 \mathrm{mv} \mathrm{dec}^{-1}$ was measured.

Carbon substrates were coated with nickel [22] by electroless and electrodeposition methods showing that the latter is more catalytically active for hydrogen evolution in alkaline media.

Mixing rare earth metal powders of Cerium or Lanthanum with $\mathrm{Ni}$, electrodes were prepared by generation of a solid solution [23]. The synthesis was realized at $500^{\circ} \mathrm{C}$ forming $\mathrm{CeO}_{2}$ and $\mathrm{NiO}$ while with $\mathrm{La}, \mathrm{LaNiO}_{3}$ particles transformed to $\mathrm{La}_{4} \mathrm{Ni}_{3} \mathrm{O}_{10}$ allowing a particle size increment. Also the formation of the intermetallic $\mathrm{LaNiO}_{3}$ favors current densities for the hydrogen evolution reaction. Ni-Mo alloys [24] are also materials that have been studied in order to increase the chemical stability of Ni-based electrodes. Studies on these materials have shown the formation of intermetallic $\mathrm{Ni}_{4} \mathrm{Mo}$ compounds presenting an adequate stability for the hydrogen evolution reaction. 
Electrodes made with Ni-Ti alloys [25], prepared by thermal arc spraying, presented catalytic activity that improves with Ti content. Previously Ni-Ti was added with aluminum for a leaching process, allowing a better activation. For this system, it was found that using electrochemical techniques the HER takes place via the Volmer-Heyrosky mechanism.

Coating layers of $\mathrm{NiCu}$ [26], prepared by electrodeposition of $\mathrm{Cu}-\mathrm{Ni}$, present a compact non homogenous structure, which gives the material a good stability, i.e. corrosion resistance during electrolysis studies. These electrodes also presented good electrical conductivity also giving advantageous features during the electro-oxidation process.

The EIS analysis confirms that Ni-Bi [27] alloys show that charge transfer resistances decrease and the double layer capacitance values increase for binary coatings. An improvement in catalytic activity for the alloys in the range of $0.22 \%$ to $0.49 \%$ in weight of $\mathrm{Bi}$ of composition was shown compared to nickel electrodes.

The formation of amorphous alloys, contributes to develop larger specific area materials compared to nickel alloys. For example, Ni-S-Mn based alloy showed an improved performance and better stability for the Hydrogen evolution reaction [28]. This was achieved by the co-deposition of $\mathrm{Ni}, \mathrm{S}$ and $\mathrm{Mn}$, using a galvanostatic method. It was found that the catalytic activity of Ni-S compound decays due to leaching induced by the presence of sulfur. Recently, it was reported work on nickel amorphous alloys using boron, niobium and tantalum [29], and other similar Ni-Mo-B based alloys. From that work it was concluded that the $\mathrm{Ni} 66.5 \mathrm{Mo}_{28.5} \mathrm{~B}_{5}$ and $\mathrm{Ni}_{63} \mathrm{Mo}_{27} \mathrm{~B}_{10}$ alloys have better catalytic activity. The authors also tested $\mathrm{Nb}$, Ta and $\mathrm{Si}$ based materials and reported hydrogen absorption.

Some studies [30] have reported the making of electrodes using PTFE as binder for nickel Raney, as well as some additives to study the charge/discharge properties during ageing and polarity changes. From these studies it was found that nickel Raney added with PTFE increased its electroactive area in 102-103 times compared to the geometric area. Using $\mathrm{Ti}, \mathrm{Cr}$ and $\mathrm{Fe}$ as additives a stable electrochemical performance was seen at $60^{\circ} \mathrm{C}$.

Changing growth conditions during electrodeposition process showed an effect on catalytic properties of nickel alloys, in particular $\mathrm{Ni}-\mathrm{W}$, which grown under super gravity conditions [31], tends to develop a finer grain size therefore, increasing its electroactive and considerably reducing microcraks, showing a better corrosion performance.

\section{Preparation and characterization of Raney nickel}

Many features of Raney nickel that favor the use of electrodes for the generation of hydrogen derive from its original microstructural properties. In figure 3 , the $\mathrm{Ni}-\mathrm{AI}$ equilibrium phase diagram [32] shows the different phases that are obtained when $\mathrm{Ni}$ and $\mathrm{Al}$ are combined in different proportions. This diagram is characterized by a liquid phase, a face-cubic-center (fcc) phase at both the $\mathrm{Al}$ and $\mathrm{Ni}$ rich ends, a non-congruently melting compound $\mathrm{Al}_{3} \mathrm{Ni}$ and three intermediate phases with a variable range of solubilities, $\mathrm{AI}_{3} \mathrm{Ni}_{2}$, $\mathrm{AlNi}$ and $\mathrm{AlNi}$. When the $\mathrm{Ni}-\mathrm{Al}$ alloys (Ni between of $40-50 \mathrm{wt} . \%$ ) are melted at $1300^{\circ} \mathrm{C}$, 
the alloys are located in the area of $\beta\left(\mathrm{Ni}_{2} \mathrm{Al}_{3}\right.$ phase $)+$ liquid. After melting and quenching, the system may either keep the phase compositions at high temperatures $(\beta)$ or rich the equilibrium phases reach in $\delta$, depending on the quenching rate, being transferred to the area of lower temperatures, namely the area of $\delta\left(\mathrm{Ni}_{2} \mathrm{Al}_{3}\right.$ phase $)+$ liquid $\left(\mathrm{NiAl}_{3}+\delta\right)$, if the cooling rate is not too high. So the content of the $\mathrm{Ni}_{2} \mathrm{Al}_{3}$ phase is more abundant and the $\mathrm{NiAl}_{3}$ phase becomes less abundant. Ni-Al alloys (Ni/Al 50/50 w/w) are in equilibrium in the phase area of $\mathrm{NiAl}_{3}+\delta\left(\mathrm{Ni}_{2} \mathrm{Al}_{3}\right.$ phase $)$ when they are cooled by ambient cooling.

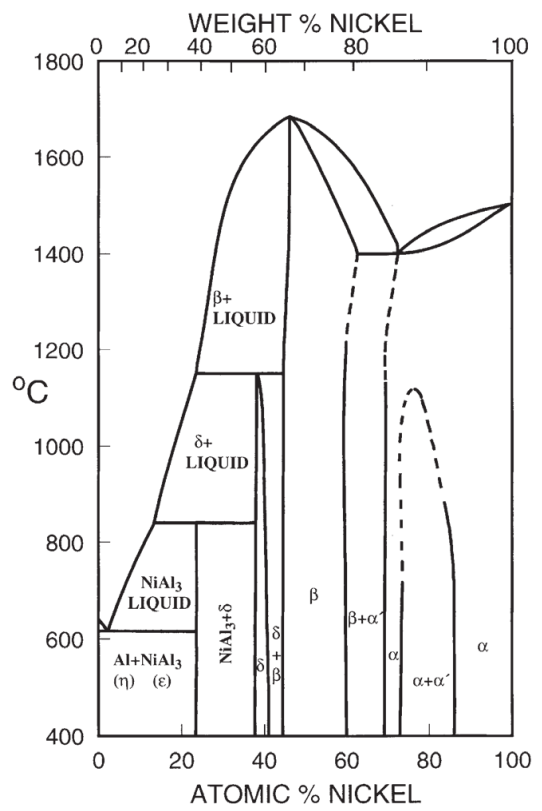

Figure 3. Phase diagram of Ni-Al alloy

As mentioned earlier nickel Raney was first elaborated by Murray Raney, who registered its invention in 1927 (US patent No. 1628190). The main use of the material at that time was for hydrogenation of oils, fats and waxes. At present this material is still used in that industry; its use as a catalyzer for alkaline electrolysis was later proposed. To make skeletal nickel, this metal and aluminum in the form of powder, granules or solid are used. Nickel Raney is $\mathrm{Ni}-\mathrm{Al}$ alloy with high catalytic features besides being a low cost material as its preparation does not require noble metals. It presents a spongy skeletal morphological structure. Its generic name derives from that. Its grain size reaches a nanometric range.

Due to its activity and selectivity, it can be used to promote various reactions. It is used in the partial hydrogenation of acetylene compounds, reduction of 1-(nitrometil)-cyclohexane. In alkaline solution reduces - $\mathrm{CO}-$ to $-\mathrm{CHOH}$ - and ArCO- to ArCH3-. In its skeletal form, nickel can be used for hydrogenolysis of sulfur compounds, desulfurization of thiophene, desulfurization of ethylene-thioacetals. It also catalyzes the reduction of carbonyl groups, either double or triple activated links. 
In the conventional technique used for making Ni Raney, this metal and aluminum are melted together in the desired proportion (typically 50\% weight each) and let cooled down at ambient conditions. After that, a leaching process follows using a soda solution to dissolve most of the aluminum and leaving behind a highly porous structure in the remaining nickel, that act as active sites. Other techniques for the preparation of Raney nickel electrodes include the co-electrodeposition of both metals to create the wanted alloy. Sintering of nickel and aluminum polysilicates is another method to make nickel Raney. In this process, several are grown on a substrate and then an interdifusion process is promoted. Mechanical alloying is another technique recently used for the making of skeletal nickel.

During the leaching process, the alloy is immersed in a sodium hydroxide solution $(\mathrm{NaOH})$ which action produces a high surface area porous material. In general aluminum is alloyed to nickel as aluminum dissolves in alkaline solutions, but other metals can be used too. With aluminum a proportion of $50 \%$ weight is used but using other metals may require other compositions to attain the desired properties. The leaching process is also time dependent, the longer the process, the more aluminum is dissolved and more porous will form. Lesser times can be used to allow some aluminum to remain in the final electrodes but less skeletal features will be produced reducing the active surface area.

$$
2(\mathrm{Ni}-\mathrm{Al})_{\mathrm{s}}+2 \mathrm{OH}^{-}+6 \mathrm{H}_{2} \mathrm{O} \rightarrow 2 \mathrm{Ni}-\mathrm{Raney}+2 \mathrm{Al}(\mathrm{OH})_{4}(\mathrm{aq})+3 \mathrm{H}_{2}(\mathrm{~g})
$$

During leaching hydrogen gas is also released considering this as an activating process as hydrogen is easily adsorbed mainly by aluminum. As early as 1947 it was reported [33] that aluminum absorbs very large quantities of hydrogen and although electrochemical processes occur at the surface level, hydrogen has been reported to move around in metal lattices, especially defects such as grain boundaries allowing hydrogen reach the surfaces of the metal. These features have allowed the development of metal-hydrogen systems such as $\mathrm{NiMH}$ batteries as well as the Al containing Mischmetal alloy used in hydrogen storage [34] where high hydrogen desorption rates have allowed the development of both technologies at the commercial level. This ease in hydrogen availability can be seen as a catalytic feature that gives Ni Raney its high activity for many hydrogen-involving reactions. On the other hand, hydrogen absorption on metals is known to be a fast process [35], with hydrogen interacting in three principal ways: (i) by dissociative chemisorption at the surface; (ii) by physical adsorption as molecules at very low temperatures; and (iii) by dissolution or occlusion. Besides these interactions there have been added many intermediate states of various features of importance in catalysis but the reader is encouraged to go directly to specialized literature.

Once the leaching process has been completed, a process to eliminate the alloy's pyrophoric properties is often applied by immersion in water of the alloy which promotes the formation of an oxide layer on top of the material stabilizing it. There have not been studies to establish the effect (adverse or not) of the stabilization process on the catalytic activity of $\mathrm{Ni}$ Raney as it has been used only to facilitate its handling. Once fabricated, from the electrocatalytic point of view, skeletal nickel will be more active and will have more surface area than pure solid nickel. 
Parameters such as temperature and reaction time, etc. affect the resulting properties of the catalyzer. The complex liquid-solid reactions can be described by the following stages: a) liquid hydroxide diffusion around solid particles b) penetration and diffusion of solution into the unreacted material's structure, c) reaction of solution with aluminum to form aluminate and hydrogen, $d$ ) diffusion of products to the outside of the forming structure and e) diffusion of products to the bulk of the solution [36]. A similar model, the shrink core model, can be used to determine the kinetics of the leaching process. This model describes the irreversible desorption of hydrogen followed by diffusion in the porous solid through the pores. When mass transfer rate of the solute in the no extracted inner part is much slower than that in the outer part, where most of the solute has been extracted, or the solute concentration is much higher than the solubility of the solute in the solvent phase, a sharp boundary may exist between the outer and the inner region. A core of inner region shrinks with the progress of the extraction. These situations can be modeled by the shrinking-core model [36]. The model is adequate to describe adsorption process, ionic interchange and solid-fluid reactions.

The effect of temperature has been reported for example for treatments at $100^{\circ} \mathrm{C}$ and $50^{\circ} \mathrm{C}$ [37]. In that work skeletal nickel showed crystal sizes from 1 to $20 \mathrm{~nm}$. Also, those values can be obtained if the temperature and caustic solution reduces.

The presence of additives during the leaching process allows better activity, either by using metals or their oxides. The purpose of these additives is to increase the surface area of the resulting material. When the $\mathrm{CuAl}_{2}$ phase is formed, the addition of $\mathrm{Zn}$ to form $\mathrm{Cu}(\mathrm{Zn}) \mathrm{Al}_{2}(\mathrm{~s})$ [38] improves the leaching process by allowing a higher surface area of skeletal copper by the dissolution of these additives.

In nickel Raney the phases identified are a mixture of $\mathrm{NiAl}_{3}, \mathrm{Ni}_{2} \mathrm{Al}_{3}$ and the eutectic phases of $\mathrm{Al}_{-\mathrm{NiAl}}$. Such phases are seen with $\mathrm{Ni}$ :Al 50\%-50\% and $31.5 \%-68.5 \%$ in weight percent [39]. $\mathrm{NiAl}_{3}$ and the eutectic phases are very reactive in sodium hydroxide solution so that aluminum is dissolved, forming the skeletal configuration of nickel. Although the $\mathrm{Ni}_{2} \mathrm{Al}_{3}$ phase reacts at a slower rate, rising the temperature above $50^{\circ} \mathrm{C}$ it reacts faster, decomposing at boiling temperature.

It has been recently reported [40] that using nickel powder with $\mathrm{Ni}-14 \% \mathrm{Al}$, in a mechanical mill the inter-metallic $\mathrm{NiAl}_{3}$ compound is formed. Microstructure studies using Synchrotron X-ray micro tomography [41] on nickel Raney (50\%-50\%) synthesized by a gas atomization process, revealed the presence of several grain sizes. The authors report an improvement in its hydrogenation capacity when synthesized with grain sizes of 106 to 150 microns. This was achieved by the addition of metals to the intermetallic $\mathrm{NiAl}_{3}$. Other studies [42] using B, $\mathrm{Zr}, \mathrm{Cr}$ and Mo showed that the intermetallic compound $\mathrm{NiAl}_{3}(\mathrm{~B}, \mathrm{Zr})$ presents the best corrosion resistance, in alkaline medium.

By the spraying technique nickel Raney was prepared using different Ni:Al proportions going from $65 \%$ to $75 \% \mathrm{Al}$ weight, founding that by cooling the metal during the spraying its rugosity is improved, obtaining more $\mathrm{NiAl}_{3}$ phase allowing by that a better electrocatalytic performance. 


\section{Final remarks}

Skeletal or nickel Raney has proved to be a very interesting and costly effective system for the catalysis of both chemical and electrochemical reactions. Having said that, it is also recognized that the several factors involved in its preparation affect the performance of the final product, i.e. type of metals in the alloy, their proportion (i.e. composition), used additives, solution concentration and time and temperature during the leaching stage. Possibly its final conditioning to eliminate its pyrophoricity, could affect its catalyzing properties but little has been investigated in this respect. As with any electrocatalysts, conditions at the surface have a great influence on the product's properties, e.g. crystalinity, crystal planes, defects (grain boundaries, stepped and kinked surfaces, etc.), rugosity/porosity, i.e. surface area, microstructure such as the type of phases (metallic, intermetallic, other compounds), grain/particle sizes, and other structural features like the presence of clusters and other agglomerates. In this respect, it should also be mentioned the efforts in the preparation of amorphous materials to increase corrosion resistance and surface area. Among combined materials for improving nickel properties there have been efforts in testing metals such as $\mathrm{Pt}, \mathrm{Pd}, \mathrm{Ti}, \mathrm{Zr}, \mathrm{Cr}, \mathrm{Bi}, \mathrm{La}, \mathrm{Co}, \mathrm{Zn}, \mathrm{Ag}, \mathrm{Cu}, \mathrm{Fe}, \mathrm{Mn}, \mathrm{Nb}, \mathrm{Mo}$, and others, as well as the addition of $\mathrm{C}, \mathrm{S}, \mathrm{B}$, etc.

Corrosion resistance is also a property sought in new electrode systems. Nevertheless, many metals passivated in alkaline media which may change their surface properties including catalytic performance. Both features, corrosion resistance and catalytic performance, should be sought simultaneously and it should include the evaluation of the effect of the presence of oxides and hydroxides on the electrode surface in alkaline media.

Different manufacturing routes have also been tested such as conventional melt alloying, mechanical alloying, arc gas spraying, electrodeposition, electroless coating, laser alloying of aluminum with electrodeposited nickel [43], interdiffusion of more than one electrodeposited layer, etc.

During the leaching stage, additives or alloying components have been used to promote several effects on the final product. Materials tested for better leaching process results include metals like $\mathrm{Cu}, \mathrm{Zn}$ and also oxides. Certainly, other parameters such as temperature and reaction time during leaching are tested especially for new systems as these can change compared to conventional Ni alloys.

Although there have been reports on improvement catalyzers for the HER, many proposed systems still include platinum, while the economics is still recognized as one of the main challenges to overcome. For this reason, the most used composition in alkaline electrolysis is still the 50/50 weight percent nickel with aluminum, but many laboratory results show new systems with great potential, including higher exchange current densities and corrosion resistance, to be incorporated in economical commercial hydrogen production systems. 


\section{Author details}

A.M. Fernández

Universidad Nacional Autónoma de México, México

U. Cano

Instituto de Investigaciones Eléctricas, México

\section{References}

[1] Presentation on alkaline electrolysis from IEA/HIA Task 25, High temperature Hydrogen Production Process, http://www.ieahia.org

[2] Hydrogen and Fuel Cells Program Plan, the U.S. Department of Energy, September 2011

[3] www.acagen.com

[4] Andrew D Moore, Barbara Nebel, Simon Whitehouse, Final Report, Hydrogen Production from Renewable Energy by Electrolysis, PE Australasia Ltd., CREST Project 1.2.3, Centre for Research into Energy for Sustainable Transport (CREST), Perth, Australia, March 2010.

[5] Martínez-Millán Wenceslao, Ph.D. Thesis, CIE-UNAM, México, September 2006

[6] W. Martínez, A. Fernández, U. Cano-Castillo, "Synthesis of nickel-based skeletal catalyst for an alkaline electrolyzer", International Journal of Hydrogen Energy, Volume 35, Issue 16, August 2010, 8457-8462, 2010.

[7] Ram Subbaraman, Dusan Tripkovic, Dusan Strmcnik, Kee-Chul Chang, Masanobu Uchimura, Arvydas P. Paulikas, Vojislav Stamenkovic, Nenad M. Markovic, Enhancing Hydrogen Evolution Activity in Water Splitting by Tailoring Li+-Ni(OH)2-Pt Interfaces, SCIENCE, vol 334, 2 December 2011, www.sciencemag.org.

[8] Jerzy Chlistunoff, Final Technical Report, Advanced Chlor-Alkali Technology, LAUR 05-2444, DOE Award 03EE-2F/ED190403, Project Period 10:01 - 09:04, Los Alamos National Laboratory, Los Alamos, NM 87544

[9] B. Kroposki, J. Levene, and K. Harrison, P.K. Sen, F. Novachek, Technical Report, NREL/TP-581-40605, September 2006, Electrolysis: Information and Opportunities for Electric Power Utilities.

[10] Richard Bourgeois, Alkaline Electrolysis, Final Technical Report, Award DE-FC3604GO14223, General Electric Global Research Center, 31 March 2006

[11] Michael Stichter, Final Technical Report, Reporting Period:02/01/2004 to 09/30/2007, Hydrogen Generation from Electrolysis, DOE Award \# DE-FC36-04GO13028; Amendment No. A002.

[12] Bao Jin-Zhen, Wang Sen-Lin, Acta Phys-Chim. Sin. 2011, 27 (12), 2849-2856

[13] C. Lupi, A. Dell'Era, M. Pasquali, Int. J. of Hydrogen Energy 34(2009)2101-2106.

[14] I. Herraiz-Cardona, E. Ortega, J. García Antón, V. Pérez-Herranz, Int. J. of Hydrogen Energy 36(2011)9428-9438.

[15] I. Herraiz,-Cardona, E. Ortega, V. Perez-Herranz, Electrochimica Acta 56(2011)13081315 
[16] Ramazan Solmaz, Gu lfeza Kardas, Energy Conversion and Management 48 (2007) 583591

[17] M. Jafarian, O. Azizi, F. Gobal, M.G. Mahjani, Int. J. of Hydrogen Energy 32(2007)16861693.

[18] R. Solmaz, A. Döner, I. Sxahin, A.O. Yü ce , G. Kardasx, B. Yazıcı, M. Erbil, Int. J. of Hydrogen Energy 34(2009)7910-7918.

[19] Ramazan Solmaz, Gülfeza Kardas, Electrochimica Acta 54 (2009) 3726-3734.

[20] L.J. Song, H.M. Meng, Int. J. of hydrogen Energy 35(2010)10060-10066.

[21] Reza Karimi Shervedani, Ali Reza Madram, Electrochimica Acta 53 (2007) 426-433.

[22] : Boguslaw Pierozynski and Lech Smoczynski, J. of The Electrochemical Society, 156(9)(2009)B1045-B1050

[23] M.A. Domínguez-Crespo, A.M. Torres-Huerta, B. Brachetti-Sibaja, A. Flores-Vela, Int. J. of Hydrogen Energy 36(2011)135-151

[24] N.V. Krstajic', V.D. Jovic',, Lj. Gajic'-Krstajic', B.M. Jovic', A.L. Antozzi, G.N. Martelli, Int. J. of Hydrogen Energy 33(2008)3676-3687.

[25] Andrea Kellenberg, Nicolae Vaszilcsin, Waltraut Brandl, and Narcis Duteanu, Int. J. of Hydrogen Energy 32(2007)3258-3265.

[26] Ramazan Solmaz, Ali Döner, Gülfeza Kardas, Int. J. of Hydrogen Energy 34(2009)20892094.

[27] Mehmet Erman Mert, Gülfeza Kardas, J. of Alloys and Compounds 509(2011)9190-9194.

[28] Zhongqiang Shan,Yanjie Liua, Zheng Chen, GarryWarrender, Jianhua Tian, Int. J. of Hydrogen Energy 33(2008)28-33.

[29] L. Mihailov, T. Spassov, I. Kanazirski, I. Tsvetanov, J Mater Sci 46 (2011)7068-7073.

[30] Paolo Salvi, Paolo Nelli, Marco Villa, Yohannes Kiros, Giovanni Zangari, Gianna Bruni, Amedeo Marini, Chiara Milanese. Int. J. of Hydrogen Energy 36(2011)7816-7821.

[31] Mingyong Wanga, Zhi Wang, Zhancheng Guo, Zhaojun Li, Inter J. of Hydrogen Energy 36(2011)3305-3312.

[32] A Pasturel, C Colinet, AT Paxton: and M van Schilfgaarde, J. Phys: Condens. Matter 4 (1992) 945-959.

[33] C. E. Ransley \& H. Neufeld, Absorption of Hydrogen by Aluminium Attacked in Caustic Soda Solution, Nature, 159, 709-710 (24 May 1947)

[34] Y Osumi, A Kato, H Suzuki, M Nakane, Hydrogen absorption-desorption characteristics of mischmetal-nickel-aluminum alloys, Journal of the Less Common Metals, Volume 66, Issue 1, July 1979, Pages 67-75 1979

[35] Geoffrey C. Bond, Chapter 3. Chemisorption and Reactions of Hydrogen, in MetalCatalysed Reactions of Hydrocarbons, Fundamental and Applied Catalysis book series, 2005, pp93-152, DOI 10.1007/0-387-26111-7_3,

[36] O. Levenspiel, Chemical Reaction Eng., 2nd edition, pag 371, (Wiley International Ed., 1972).

[37] M.S. Wainwright, in G. Erl, H. Knozinger, J. Weitkamp (Eds.) Handbook of Heterogeneous Catalysis, vol. 1, VCH, New York, 1997, pp. 64-67.

[38] A.J. Smith, D.L. Trimm, Ann. Rev. Mat Res. 2005, 35:127-42. 
[39] F. Devred, A.H. Gieske, N. Adkins, U. Dahlborg, C.M. Bao, M. Calvo-Dahlborg, J.W. Bakker, B.E. Nieuwenhuys, Applied Catalysis A:General 356(2009)154-161.

[40] Hongxing Dong, Ting Lei, Yuehui He, Nanping $\mathrm{Xu}$, Baiyun Huang, C.T. Liu, : International Journal of Hydrogen Energy 36(2011)12112-12120.

[41] F. Devred, G. Reinhart, G.N. Iles, B. van der Klugt, N.J. Adkings, J.W Bakker, B.E. Nieuwenhuys, Catalysis Today 183(2011)13-19.

[42] Grzegorz D. Sulka, Pawel Jozwik, : Intermetallics 19(2011), 974-981.

[43] J.Senthil Selvan, G Soundararajan, K Subramanian, Surface and Coatings Technology, Volume 124, Issues 2-3, 21 February (2000), Pages 117-127. 